\title{
Flipping the switches: CD40 and CD45 modulation of microglial activation states in HIV associated dementia (HAD)
}

Jon Salemi ${ }^{1}$, Demian F Obregon ${ }^{1,2}$, Anthony Cobb ${ }^{1}$, Spenser Reed ${ }^{1}$, Edin Sadic ${ }^{1}$, Jingji Jin ${ }^{1}$, Francisco Fernandez ${ }^{1,2}$, Jun Tan ${ }^{1,2,3}$, Brian Giunta ${ }^{1,3^{*}}$

\begin{abstract}
Microglial dysfunction is associated with the pathogenesis and progression of a number of neurodegenerative disorders including HIV associated dementia (HAD). HIV promotion of an M1 antigen presenting cell (APC) - like microglial phenotype, through the promotion of CD40 activity, may impair endogenous mechanisms important for amyloid- beta (A $\beta$ ) protein clearance. Further, a chronic pro-inflammatory cycle is established in this manner. CD45 is a protein tyrosine phosphatase receptor which negatively regulates CD40L-CD40-induced microglial M1 activation; an effect leading to the promotion of an M2 phenotype better suited to phagocytose and clear A $\beta$. Moreover, this CD45 mediated activation state appears to dampen harmful cytokine production. As such, this property of microglial CD45 as a regulatory "off switch" for a CD40-promoted M1, APC-type microglia activation phenotype may represent a critical therapeutic target for the prevention and treatment of neurodegeneration, as well as microglial dysfunction, found in patients with HAD.
\end{abstract}

\section{The Role of Microglia in HIV Associated Dementia (HAD)}

Macrophages and microglia compose some $12 \%$ of the cells in the central nervous system (CNS) [1]. Their roles include phagocytosis, antigen presentation, as well as generation and excretion of cytokines, eicosanoids, complement components, and excitatory amino acids (EAA) including, glutamate, oxidative radicals, and nitric oxide (NO) [2]. At least three phenotypic states of microglia exist based on developmental and pathophysiologic studies: (i) resting, ramified; (ii) activated nonphagocytic (or APC like) found in areas involved in central nervous system (CNS) inflammation; and (iii) reactive, phagocytic microglia observed in areas of trauma or infection [3-7] (Figure 1).

In regard to activation, macrophages and microglia are able to polarize into two major subtypes, categorized as $M 1$ or $M 2$ [8,9]. The "classical" or $M 1$ subtype overproduces pro-inflammatory cytokines and promotes

\footnotetext{
* Correspondence: bgiunta@health.usf.edu

'Department of Psychiatry and Neurosciences, Neuroimmunology Laboratory, University of South Florida, College of Medicine, Tampa, FL 33613, USA

Full list of author information is available at the end of the article
}

cell-mediated immunity $[8,9]$. It is marked by production of high levels of interferon -gamma (IFN- $\gamma$ ), tumor necrosis factor (TNF)- $\alpha$, interleukin (IL)-1, IL-12, and low levels of IL-10. The M1 phenotype may be activated when microglia contact HIV proteins (such as transactivator of transcription [Tat]) [10] bind toll-like receptors 3 or 4 as well [11]. "Alternatively activated" or $M 2$ microglia tend to dampen inflammation, clear cellular debris (including amyloid plaques), and produce very low levels of TNF- $\alpha$, IL-1, IL-12 and high amounts of anti-inflammatory IL- 10 and transforming growth factor (TGF) $\beta$, and SOCS (suppressor of cytokine signaling) $[8,9,12,13]$. These two phenotypes, respectively, correspond to the type $i i$ or $i i i$ microglial states described in the preceding paragraph. Further, the factors which cause polarization to $M 1$ or $M 2$ reinforce the maintenance of that phenotype in a cycle-like manner (Figure 1). Increased $M 1$ polarization is consistent with increased TNF- $\alpha$ observed in plasma and brain specimens in HAD and AD, and may play a role in the pathophysiology of both diseases [14].

Stimulation of Th1 and Th2 immune response by microglia is dependent upon the expression of specific
C Biomed Central

() 2011 Salemi et al; licensee BioMed Central Ltd. This is an Open Access article distributed under the terms of the Creative Commons Attribution License (http://creativecommons.org/licenses/by/2.0), which permits unrestricted use, distribution, and reproduction in any medium, provided the original work is properly cited. 


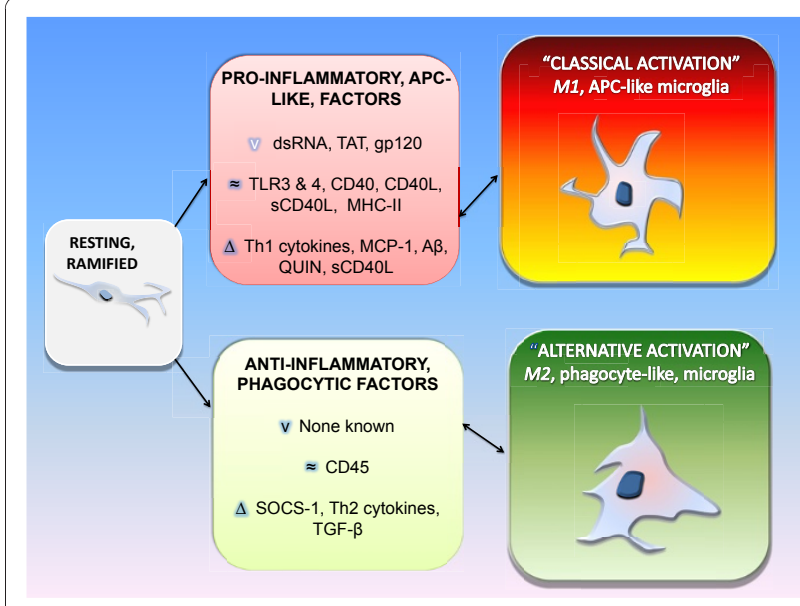

Figure 1 Modulation of Microglia Phenotypes in HIV associated dementia (HAD). The roles of microglia include phagocytosis, antigen presentation, as well as generation and excretion of cytokines, eicosanoids, complement components, and excitatory amino acids (EAA) including, glutamate, quinolinic acid (QUIN), oxidative radicals, and nitric oxide (NO) [2]. At least three phenotypic states of microglia exist based on developmental and pathophysiologic studies: (i) resting, ramified; (ii) activated nonphagocytic (or APC like) found in areas involved in central nervous system (CNS) inflammation; and (iii) reactive, phagocytic micorglia observed in areas of trauma or infection [3-7]. In regard to activation, these cells are able to polarize into two major subtypes: M1 or M2 $[8,9]$. M1 subtype over-produces pro-inflammatory cytokines. It is marked by production of high levels of interferon -gamma (IFN- $\gamma$ ) tumor necrosis factor (TNF)- $\alpha$, interleukin (IL)- 1 , IL-12, and low levels of IL-10 $[8,9]$. The $M 1$ phenotype may be activated when microglia contact HIV proteins (such as transactivator of transcription [Tat]) [10] or bind toll-like receptors 3 or 4 as well [11]. M2 microglia dampen inflammation, become phagocytic, and produce very low levels of TNF- $\alpha, \mathrm{IL}-1, \mathrm{IL}-12$ and high amounts of anti-inflammatory IL- 10 and transforming growth factor (TGF)- $\beta$, and SOCS (suppressor of cytokine signaling) $[12,13]$. These two phenotypes, respectively, correspond to the type ii or iii microglial states described in the preceding paragraph. Further, the factors which cause polarization to $M 1$ or $M 2$, reinforce the maintenance of that phenotype in a cycle-like manner $[8,9]$ (Figure 1). Increased $M 1$ polarization is consistent with increased TNF- $\alpha$ observed in plasma and brain specimens in $\mathrm{HAD}$ and $\mathrm{AD}$, and may play a role in the pathophysiology of both diseases [14]. Stimulation of Th1 and Th2 immune response by microglia is dependent upon the expression of specific molecules including major histocompatibility complex (MHC) $\|$ and CD40 [15]. $v=$ viral factors $\sim=$ soluble or cell surface receptor ligation $\Delta=$ cytokines and soluble factors.

molecules including major histocompatibility complex (MHC) II and CD40 [15]. Microglia expressing MHC II induce CD4+ T cells to generate IFN- $\gamma$ and TNF- $\alpha$ [16]. In the case of both HAD and $\mathrm{AD}$, this response is considered harmful to the brain and in both diseases TNF$\alpha$ is elevated to neurotoxic levels while only in HAD is IFN- $\gamma$ is prominently elevated [14].

In HIV associated dementia (HAD; also known as NeuroAIDS, or HIV encephalitis [HIVE]), microglia and macrophages are productively infected by HIV-1 and show diffuse inflammatory activation, which ultimately leads to neuronal damage, death, CNS dysfunction $[17,18]$. A clinical trial using a small number of post-mortem HIV-infected individuals showed a direct correlation between microglial activation/infection and cognitive decline [19]. Studies have found microglial HIV infection as central in exacerbating HIV dementia [20,21]. Importantly, neuronal dysfunction and death in HIV infection results from cytokine stimulation, but especially several cytokine-mediated apoptotic mechanisms emanating from microglia. Thus microglial cytokine production is central to the pathogenesis of HAD $[22,23]$.

Indeed, viral infection and/or immune activation of microglia fuels HAD pathogenesis ending in neuronalinjury and death $[24,25]$. Microglia are the main target for the HIV-1 infection in the brain. The virus infiltrates the CNS via infected monocytes [26,27]. Once infected or activated by HIV- proteins such as gp120 or Tat, microglia begin to excrete endogenous pro-inflammatory cytokines of the $M 1$ subtype [28].

Histopathologically, activated microglia represent a highly accurate correlate to neuronal death and damage in CNS [29]. Severity of dementia in persons with HAD is strongly correlated with the number of activated macrophages and microglia within the basal ganglia and frontal lobes [30,31]. Moreover, activation of microglial cells by HIV is associated with astrogliosis, myelin pallor, and severe neuronal loss [24,30].

Recently, with the advent of highly active antiretroviral therapy (HAART) patients with HIV have been living significantly longer lives. While HAART has been increasing the lifespan of those infected with HIV, it has also led to an increased prevalence of HAD [32-38]. As the pathology of HAD, like Alzheimer's Disease (AD), is commonly characterized by an increase in the amount of amyloid-beta (A $\beta$ ) peptide in the brain [39], evidence suggesting microglia modulate the clearance of potentially neurotoxic $A \beta$ species from the brain is of special importance $[40,41]$.

Indeed, microglia play a major role in the neuropathogenesis of HAD and AD in quite similar ways, although the etiology of these diseases differ greatly [14]. Neuropathological similarities between HAD and AD include cortical neuronal loss and amyloid plaque deposition [39,42-44]. Indeed, most forms of dementia are accompanied by a widespread degeneration in the cerebral cortex - such as the plaques in $\mathrm{AD}$ brain. $\mathrm{AD}$ is thus considered a "cortical dementia." HAD is also considered to be a cortical dementia however there is also targeted damage to regions lying under the cortex. Some authors consider HAD to be a subcortical dementia however this terminology is somewhat inaccurate. HAD 
can cause damage to both cortical and subcortical areas. The resulting brain damage is often visualized on MRI as generalized brain atrophy and also visibly damaged subcortical areas $[45,46]$.

Amyloid plaques in $\mathrm{AD}$ result from the deposition of amyloid beta $(\mathrm{A} \beta)$ which is a putative pathogenic molecule in $A D . A \beta$ is the cleavage product of the amyloid precursor protein (APP) and APP mutations are associated with inherited forms of AD. The clinical implication or pathogenic consequences of brain amyloid deposition are still controversial in the AD field; although, the finding of $A \beta$ deposition in both $A D$ and HAD strongly suggests parallel pathways of chronic inflammation-mediated change that eventually yields cortical dysfunction characterized by identical "biomarkers". For example, decreased cerebrospinal fluid (CSF) $\mathrm{A} \beta$ and increased tau (a component of the neurofibrillary tangle, a second AD neuropathological hallmark) have been proposed as sensitive and specific markers of AD in several studies $[47,48]$. It has also been found that changes in CSF $A \beta$ and tau are comparable to those observed in AD and HAD patients [49]. The pathogenic significance of these biomarkers is not well established but it has been hypothesized that decreased CSF $A \beta$ indicates increased aggregation of insoluble $A \beta$ and sequestration into amyloid plaques [50].

The mechanisms of neurodegeneration, which are highly microglia-dependent, in AD and HAD are similar in many ways as well [14]. Cascades of inflammatory processes lead to neurodegeneration in both dementias. The initial step in each disease differs. HAD is secondary to infection with HIV-1, while the exact cause of $\mathrm{AD}$ remains to be established. A common feature among both diseases is the interactions of microglia which promote a neurotoxic inflammatory environment. These interactions play significant roles in the initiation and continuation of the neurodegenerative process in each disease [14].

In both diseases, whether activation is by HIV itself, its proteins, or $\mathrm{A} \beta$ peptides, microglia release cytokines, reactive oxygen species (ROS), and several neurotoxins that impair cellular function, neurotransmitter action, and induce neuronal loss $[51,52][14,53]$. Some of these neurotoxins in both forms of dementia include TNF- $\alpha$, arachidonic acid, platelet activating factors (PAF), nitric oxide (NO), and quinolinic acid (QUIN) [17,53-59]. Nitric oxide is synthesized by endothelial cells, neurons, and macrophages and is thought to be associated with NMDA-type glutamate-initiated neurotoxicity [54].

TNF- $\alpha$ is released by HIV-1-infected microglia, and oligodendrocytes are particularly sensitive to its effects [60]. Steady-state levels of TNF- $\alpha$ mRNA are higher in the subcortical regions of the CNS of patients with HAD than in HIV-1-infected patients without CNS involvement [61]. QUIN is a highly excitotoxic marker most well known in HIV neurological disease which may reflect the extent of immune activation in both blood and the brain and correlates with systemic and neurological disease status [17,53,55-59].

During immune activation, particularly while levels of IFN- $\gamma$ are increased, induction of the enzyme indoleamine 2,3-dioxygenase occurs, increasing the synthesis of QUIN [53,62-64]. HIV-infected microglia also release chemokines [65], which may enhance infiltration and recruitment of both infected and uninfected microglia [53].

HIV encephalitis is typically marked by the presence of multinucleated giant cells and microglial nodules by immunohistochemistry or in situ hybridization. The presence of microglia in the CNS is strongly associated with severe neurobehavioral complications [66-69]. Microglia, as a major target of HIV-1 infection in the CNS, are typically a viral reservoir [70-72] and are also key in HIV-1 neuroinvasiveness-penetration into the CNS by the virus [72,73]. Most importantly, a discrepancy between the localization of HIV-infected cells and the severity of neurocognitive symptoms has been described [74-76]. Thus, other mechanisms secondary to virus infection, such as passage of monocytes and lymphocytes into the brain, activation of astrocytes/microglia, and production and release of inflammatory cytokines, all participate in the pathogenesis of HAD. This is a key concept which makes the neuropathogenesis of HAD, in many ways, similar to that of AD.

$\beta$-amyloid is a potent and direct neurotoxic agent [77-79], much like the HIV-1 proteins gp120 and Tat, and it induces a cascade of cellular mechanisms including activation of microglia [80], which leads to neuronal damage [81]. Indeed, reactive microglia are closely associated with neuritic and $\beta$-amyloid plaques, just as they are with HIV1 Tat protein [82-89]. Using electron microscopic techniques, interactions between microglia and astrocytes have been observed [90], which may be associated with the production of cytokines that are also over-produced in the HAD brain such as IL-1 $\beta$, tumor TNF- $\alpha$, complement proteins, and ROS [81,91-94]. Research by our group and others of the microglia signal transduction pathways mediating the neurotoxic response of $A \beta$ demonstrated that mitogen-activated protein-kinase (MAPK) superfamily members ERK1/2 and p38 MAPK act as mediators [95-97]. Furthermore, several lines of evidence indicate the NF- $\kappa \mathrm{B}$ in microglia is stimulated by $\beta$-amyloid $[98,99]$. Activation of NF- $\kappa \mathrm{B}$ can stimulate transcription of genes expressing TNF- $\alpha$, IL-1, IL-6, monocytes chemo-attractant protein-1(MCP-1), and nitric oxide synthase (NOS). This too is re-capitulated in HAD as several lines of evidence indicate HIV gp120 and Tat activate the same pathway, leading to the production of the same neurotoxins [88,89,100-103]. 
Adding biological "insult to injury," in the HIV-1 infected brain, microglial phagocytosis of $A \beta_{1-42}$ peptide appears inhibited [35]. The deposition of $A \beta$ plaques in the HIV-1 infected brain is likely caused by several factors including the effects of cytokines and HIV-1 proteins on microglial phenotype, activation and activity. IFN- $\gamma$ is hypothesized to enhance the effects of HIV-1 Tat by promoting the switch from a microglial phagocytic phenotype to one that is an antigen presenting cell (APC) phenotype [37].

\section{Modulation of Microglial activation in HAD: CD40, CD40L, sCD40L and CD45}

CD40L is a $33-\mathrm{kDa}$ type II membrane glycoprotein that is predominantly expressed by activated T cells, B cells, myeloid cells, and platelets. It has been well established that CD40L upregulates the immune response by leading to increased CD4+ T cell activation; an effect which promotes the replication of HIV in infected lymphocytes and immune cells [104] and also that robust CD40 ligation promotes an inflammatory and neurotoxic environment in the brain $[105,106]$.

Elevated levels of sCD40L are found in an array of neurodegenerative diseases including HAD, AD, and multiple sclerosis (MS) [106]. This soluble protein is thought to initiate or potentiate an inflammatory cycle [106-109] in these conditions. Indeed, inflammation upregulates expression of CD40 receptor on the surface of endothelial cells and the shedding of the ligand [110]. Inhibition of CD40-CD40L interactions was shown to retard the development of experimental autoimmune encephalomyelitis (EAE), in an animal model of MS [111]. In vitro studies demonstrated IFN$\gamma$, which is overexpressed in the HIV infected brain [112] up-regulates the expression of CD40 by microglia $[113,114]$. In AD it has been shown that blood vessels and reactive microglia stain positively for CD40 in post-mortem brain tissues. Also in AD brain, aggregates of reactive microglia express CD40 in senile plaques. Up-regulation of CD40 expression by microglia is also seen in a variety of brain lesions without $A \beta$ deposits. They include multiple sclerosis plaques [111] as well as lesions of adrenoleukodystrophy, DRPLA, and ischemic strokes [115]. A $\beta$ was also shown to induce CD40 expression by cultured microglia $[116,117]$ and cultured vascular endothelial cells [116,118][118-120]. HIV-1 induces the latter phenomenon as well [121] It may be the mechanism by which CD40 expression is up-regulated in and around senile plaques in both diseases. However, the results of this study suggest that CD40 expression is induced upon multiple stimuli and that CD40-CD40L interactions are involved rather ubiquitously in activation of microglia and vascular cells.
In regard to HIV-1 neuropathogenesis, a link between CD40 and microglia has been established. Upregulation of CD40 expression has been detected on microglia of HIV-1-infected brain tissues [28]. CD40L was also shown to potentiate the ability of HIV-1 Tat to activate monocytes and microglia leading to the overproduction of inflammatory proteins such as cytokines and chemokines [122].

Furthermore HAART is unable to modulate blood brain barrier (BBB) leakage and inflammation in HAD patients $[29,123]$ in part because it does not reduce the elevated levels of CD40 ligand (CD40L) found in the plasma and CSF of HIV-1-infected patients [122,124]. In further confirmation, other systems [125-127] have shown high levels of SCD40L can modulate CNS inflammation at the level of the BBB.

High levels of soluble CD40L in CSF and plasma of HIV-infected patients with cognitive impairment has been demonstrated as well. Exposure of primary human brain microvascular endothelial cells (BMVECs) to CD40L increased the expression of adhesion molecules intracellular adhesion molecule- 1 and vascular cell adhesion molecule-1, which yielded a fourfold increase in monocyte adhesion to BMVECs and stimulated migration across an in vitro BBB model [128].

Also central to microglial regulation in HAD, higher levels of sCD40L have been found in the blood and CSF of HIV-infected patients with cognitive impairments compared with HIV-infected subjects without cognitive impairment. Further assays from the same study showed CD40L synergized with HIV-1 Tat to increase TNF- $\alpha$ release from primary human monocytes and microglia, in an NF- $\kappa$ B-dependent manner [122].

Several basic science studies have shown that, during $\mathrm{HAD}$ as well as AD, CD40 upregulates the NF- $\kappa \mathrm{B}$ pathway, causes hyperactivity in microglia and macrophages, which then produces the release of several neurotoxic compounds such as TNF- $\alpha$ further exacerbating neurodegeneration (for further review see $[97,105,106])$. In addition, CD40 activation increases inflammatory responses and decreases the clearance of $A \beta$. Disrupting CD40 activation by opposing CD40L activity has shown important in improving spatial memory in animal models of AD $[117,118,129,130]$. Data from our group and others demonstrate the negative regulation of CD40 activation on microglial cells by CD45 [82].

Indeed in contrast to CD40, one cell surface receptor that has been implicated in inhibiting microglial activation is the protein-tyrosine phosphatase (PTP) protein, CD45. It is especially effective at inhibiting microglial activation because its action takes place far upstream from proinflammatory intracellular mediators. We have shown that cross linking CD45 markedly reduces microglial activation resulting from $\mathrm{A} \beta$ peptide [131]. 
Additionally, CD45 inhibits the activation of the p44/42 MAPK pathway; thereby abrogating microglial activation [131]. Mice brains deficient in CD45 have been shown to have increased levels of potentially neurotoxic cytokines such as TNF- $\alpha$ [131]. Taken together, these data seem to suggest that $\mathrm{CD} 45$ opposes microglial activation induced by the presence of $A \beta$ peptide.

In addition to its inhibitory effect on $A \beta$ induced microglial activation, CD45 has been shown to inhibit microglial activation induced by several other proinflammatory stimuli [131]. When microglia are incubated with CD45 cross-linking antibodies and LPS, activation was significantly attenuated as evidenced by decreased levels of the neurotoxins TNF- $\alpha$ and NO [131]. This suggests that cross linked CD45 acts to inhibit microglial activation induced by LPS [131]. Other studies also implicate the role of CD45 in negatively regulating cytokine receptor signaling [132,133]. CD45 sufficient macrophages were able to induce greater $\mathrm{A} \beta$ clearance, reduced proinflammatory (TNF- $\alpha$ ) and increased anti-inflammatory (IL-10) cytokines, as well as, potentiate growth factors (TGF $\beta$ ) in mouse brain. Further, CD45 has also been shown to downregulate NF-kappaB, an important mediator of proinflammatory cytokines and is expressed at a higher rate in HIV infected cells vs. normal cells [134]. Also, matrix metalloproteinase-9 (MMP-9), a protein shown to decrease $A \beta$ plaque formation, was significantly elevated following CD45 administration [135].

In using CD45 to characterize various isoforms of a microglial surface receptor target, our prior studies found that CD45 is able to antagonize CD40L/CD40 mediated-microglia activation [136]. CD45 may perform this function by modulating the production of IL-2, IL-10, and other cytokines and inflammatory factors [97]. Further, co-treatment of microglia with CD40L, in the presence of CD45 activating antibody, results in significant inhibition of microglial TNF- $\alpha$ production through inhibition of p44/42 MAPK activity [82].

In HIV infected patients CD45 expression is decreased. Although this study did not analyze HAD, a lower expression of these proteins on immune cells as well as a higher presence of CD8+ lymphocyte count in HIV+ patients, but not controls, suggests multifactorial immune dysregulation in HIV infected patient; including CD45 dysregulation [137]. Impaired functioning of CD45 is also observed in HIV infected cell cultures. Indeed dysregulated CD45 function likely plays a key role in the inhibition of $\mathrm{CD} 3 / \mathrm{CD} 4$ signaling thus contributing to HIV-1 pathogenesis [138]. CD45 antibodies can suppress HIV-infected microglial proliferation, as well as, potently inhibit HIV replication, both in vitro and in vivo. Microglia that contain CD45 agonist antibody are able to inhibit HIV-1 replication in human cells [139]. Accordingly, HIV infected T-cells display lower levels of CD45 protein; perhaps pointing to a subpopulation susceptible to virus infection or an effect of the virus or viral products on these cells. Indeed, CD45 antibodies have the potential to suppresses neuroinflammation in HAD, AD, and other inflammatory CNS diseases [27,82,131].

In summary, numerous investigations suggest that CD45 plays a key role in regulation of CD40L/CD40-induced microglial activation. This property of microglial CD45 as a regulatory "off switch" for a CD40 promoted, APC-type, M2 type microglia activation phenotype is very likely critical for the prevention and treatment of neurodegeneration found in patients with HAD (Figure 1).

\section{Abbreviations}

Aß: Amyloid beta/beta amyloid; AD: Alzheimer's disease; APP: Amyloid precursor protein; CNS: Central nervous system; CSF: Cerebrospinal fluid; CD40: Cluster of differentiation 40; CD40L: CD40 ligand; HAD: HIV associated dementia; IFN: Interferon; IL: Interleukin; NSAIDs Non-steriodal antiinflammatory drugs; sCD40: Soluble CD40; Th: T helper cell; TNF: Tumor necrosis factor; TGF: Transforming Growth Factor; SOCS: Suppressor of cytokine signaling; QUIN: Quinolinic Acid; PAF: Platelet activating factor; Tat: transactivator of transcription.

\section{Acknowledgements}

B.G. is supported by an NIH/NIMH Clinical Scientist Award (1 K08 MH08264201A1). J.T. is supported by NIH grants (1R41AG031586-01), (1R43AG03341701), and 1R43AT004871-01 as well as a Veterans Administration grant (MH080168).

\section{Author details}

'Department of Psychiatry and Neurosciences, Neuroimmunology Laboratory, University of South Florida, College of Medicine, Tampa, FL 33613, USA. ${ }^{2}$ Department of Psychiatry and Neurosciences, Rashid Developmental Neurobiology Laboratory, Silver Child Development Center, University of South Florida, Tampa, FL 33613, USA. ${ }^{3}$ Department of Molecular Medicine, University of South, College of Medicine, Tampa, FL 33613, USA.

\section{Authors' contributions}

BG was responsible for the writing of the manuscript, and addressing referee critiques. JS, AC, SR, and JJ were responsible for the initial literature search and first draft one of the review. DO contributed to the generation of Figure 1. JT provided review material for incorporation into the paper regarding the role of CD45 in neurodegeneration in the context of AD. FF provided clinical background regarding HIV and Alzheimer's-type dementias. All authors read and approved the final manuscript.

\section{Competing interests}

The authors declare that they have no competing interests.

Received: 2 August 2010 Accepted: 11 January 2011 Published: 11 January 2011

\section{References}

1. Benveniste EN: Role of macrophages/microglia in multiple sclerosis and experimental allergic encephalomyelitis. J Mol Med 1997, 75(3):165-73.

2. Banati RB, Gehrmann J, Schubert P, Kreutzberg GW: Cytotoxicity of microglia. Glia 1993, 7(1):111-8.

3. Walker DG, Kim SU, McGeer PL: Complement and cytokine gene expression in cultured microglial derived from postmortem human brains. J Neurosci Res 1995, 40(4):478-93.

4. Panek RB, Benveniste EN: Class II MHC gene expression in microglia. Regulation by the cytokines IFN-gamma, TNF-alpha, and TGF-beta. J Immunol 1995, 154(6):2846-54.

5. Frei K, Siepl C, Groscurth P, Bodmer S, Schwerdel C, Fontana A: Antigen presentation and tumor cytotoxicity by interferon-gamma-treated microglial cells. Eur J Immunol 1987, 17(9):1271-8. 
6. Suzumura A, Mezitis SG, Gonatas NK, Silberberg DH: MHC antigen expression on bulk isolated macrophage-microglia from newborn mouse brain: induction of la antigen expression by gamma-interferon. J Neuroimmunol 1987, 15(3):263-78.

7. Williams K, Bar-Or A, Ulvestad E, Olivier A, Antel JP, Yong WW: Biology of adult human microglia in culture: comparisons with peripheral blood monocytes and astrocytes. J Neuropathol Exp Neurol 1992, 51(5):538-49.

8. Mosser DM: The many faces of macrophage activation. J Leukoc Biol 2003, 73(2):209-12.

9. Gordon S, Taylor PR: Monocyte and macrophage heterogeneity. Nat Rev Immunol 2005, 5(12):953-64.

10. Bruce-Keller AJ, Barger SW, Moss NI, Pham JT, Keller JN, Nath A: Proinflammatory and pro-oxidant properties of the HIV protein Tat in a microglial cell line: attenuation by 17 beta-estradiol. J Neurochem 2001, 78(6):1315-24.

11. Suh HS, Zhao ML, Choi N, Belbin TJ, Brosnan CF, Lee SC: TLR3 and TLR4 are innate antiviral immune receptors in human microglia: role of IRF3 in modulating antiviral and inflammatory response in the CNS. Virology 2009, 392(2):246-59.

12. Akhtar LN, Tahir MY, Ahmed F, UI-Haq I, Salim KP: Suppressor of cytokine signaling 3 inhibits antiviral IFN-beta signaling to enhance HIV-1 replication in macrophages. J Immunol 185(4):2393-404.

13. Qin H, Wilson CA, Lee SJ, Benveniste EN: IFN-beta-induced SOCS-1 negatively regulates CD40 gene expression in macrophages and microglia. Faseb J 2006, 20(7):985-7.

14. Minagar A, Shapshak P, Fujimura R, Ownby R, Heyes M, Eisdorfer C: The role of macrophage/microglia and astrocytes in the pathogenesis of three neurologic disorders: HIV-associated dementia, Alzheimer disease, and multiple sclerosis. J Neurol Sci 2002, 202(1-2):13-23.

15. Ma N, Streilein JW: T cell immunity induced by allogeneic microglia in relation to neuronal retina transplantation. J Immunol 1999, 162(8):4482-9.

16. Ford AL, Foulcher E, Lemckert FA, Sedgwick JD: Microglia induce CD4 T lymphocyte final effector function and death. J Exp Med 1996, 184(5):1737-45.

17. Genis P, Jett M, Bernton EW, Boyle T, Gelbard HA, Dzenko K, Keane RW, Resnick L, Mizrachi Y, Volsky DJ, et al: Cytokines and arachidonic metabolites produced during human immunodeficiency virus (HIV)infected macrophage-astroglia interactions: implications for the neuropathogenesis of HIV disease. J Exp Med 1992, 176(6):1703-18.

18. Persidsky Y, Gendelman HE: Mononuclear phagocyte immunity and the neuropathogenesis of HIV-1 infection. J Leukoc Biol 2003, 74(5):691-701.

19. Adle-Biassette HF, Chretien L, Wingertsmann C, Hery T, Ereau F, Scaravilli M, Tardieu Gray F: Neuronal apoptosis does not correlate with dementia in HIV infection but is related to microglial activation and axonal damage. Neuropathol Appl Neurobiol 1999, 25:123-133.

20. Liu BHJ: Role of microglia in inflammation-mediated neurodegenerative diseases: mechanisms and strategies for therapeutic intervention. J Pharm Exp Ther 2003, 304:1-7.

21. BlockML Z.L, Hong JS: Microglia-mediated neurotoxicity: uncovering the molecular mechanisms. Nat Rev Neurosci 2007, 8:57-69.

22. Alirezaei MKW, Flynn CT, Brady NR, Fox HS: Disruption of neuronal autophagy by infected microglia results in neurodegeneration. PLOS ONE 2008, 3:e2906.

23. Alirezaei MKW, Fox HS: Decreased neuronal autophagy in HAD: a mechanism of indirect neurotoxicity. Autophagy 2008, 1(4(7)):963-969.

24. Avison MJ, Nath A, Greene-Avison R, Schmitt FA, Greenberg RN, Berger JR: Neuroimaging correlates of HIV-associated BBB compromise. J Neuroimmunol 2004, 157(1-2):140-6.

25. Thind K, Sabbagh MN: Pathological correlates of cognitive decline in Alzheimer's disease. Panminerva Med 2007, 49(4):191-5.

26. Sulkava R, Erkinjuntti T, Palo J: Head injuries in Alzheimer's disease and vascular dementia. Neurology 1985, 35(12):1804.

27. Cosenza MA, Zhao ML, Si Q, Lee SC: Human brain parenchymal microglia express CD14 and CD45 and are productively infected by HIV-1 in HIV-1 encephalitis. Brain Pathol 2002, 12(4):442-55.

28. D'Aversa TG, Eugenin E.A, Berman JW: NeuroAIDS: contributions of the human immunodeficiency virus-1 proteins Tat and gp120 as well as CD40 to microglial activation. J Neurosci Res 2005, 81(3):436-46.

29. Avison MJ, Nath A, Greene-Avison R, Schmitt FA, Bales RA, Ethisham A, Greenberg RN, Berger JR: Inflammatory changes and breakdown of microvascular integrity in early human immunodeficiency virus dementia. J Neurovirol 2004, 10(4):223-32.
30. Schneider JA, Boyle PA, Arvanitakis Z, Bienias JL, Bennett DA: Subcortical infarcts, Alzheimer's disease pathology, and memory function in older persons. Ann Neurol 2007, 62(1):59-66.

31. Hachiya NS, Kozuka Y, Kaneko K: Mechanical stress and formation of protein aggregates in neurodegenerative disorders. Med Hypotheses 2008, 70(5):1034-7

32. Alisky JM: The coming problem of HIV-associated Alzheimer's disease. Med Hypotheses 2007, 69(5):1140-3.

33. Simone MJ, Appelbaum J: HIV in older adults. Geriatrics 2008, 63(12):6-12

34. Repetto MJ, Petitto JM: Psychopharmacology in HIV-infected patients. Psychosom Med 2008, 70(5):585-92.

35. Keblesh JP, Reiner BC, Liu J, Xiong H: Pathogenesis of Human Immunodeficiency Virus Type-1 (HIV-1)-Associated Dementia: Role of Voltage-Gated Potassium Channels. Retrovirology 2008, 2:1-10.

36. Hult B, Chana G, Masliah E, Everall I: Neurobiology of HIV. Int Rev Psychiatry 2008, 20(1):3-13

37. Giunta B, Zhou Y, Hou H, Rrapo E, Fernandez F, Tan J: HIV-1 TAT inhibits microglial phagocytosis of Abeta peptide. Int J Clin Exp Pathol 2008, 1(3):260-75.

38. Valcour V, Shikuma C, Shiramizu B, Watters M, Poff P, Selnes OA, Grove J, Liu Y, Abdul-Majid KB, Gartner S, Sacktor N: Age, apolipoprotein E4, and the risk of HIV dementia: the Hawaii Aging with HIV Cohort. J Neuroimmunol 2004, 157(1-2):197-202.

39. Green DA, Masliah E, Vinters HV, Beizai P, Moore DJ, Achim CL: Brain deposition of beta-amyloid is a common pathologic feature in HIV positive patients. Aids 2005, 19(4):407-11.

40. Rogers J, Strohmeyer R, Kovelowski CJ, Li R: Microglia and inflammatory mechanisms in the clearance of amyloid beta peptide. Glia 2002, 40(2):260-9.

41. Rogers J, Lue LF: Microglial chemotaxis, activation, and phagocytosis of amyloid beta-peptide as linked phenomena in Alzheimer's disease. Neurochem Int 2001, 39(5-6):333-40.

42. Esiri MM, Biddolph S.C, Morris CS: Prevalence of Alzheimer plaques in AIDS. J Neurol Neurosurg Psychiatry 1998, 65(1):29-33.

43. Giunta B, Hou H, Zhu Y, Rrapo E, Tian J, Takashi M, Commins D, Singer E, He J, Fernandez F, Tan J: HIV-1 Tat contributes to Alzheimer's disease-like pathology in PSAPP mice. Int J Clin Exp Pathol 2009, 2(5):433-43.

44. Everall IP, Luthert PJ, Lantos PL: Neuronal number and volume alterations in the neocortex of HIV infected individuals. J Neurol Neurosurg Psychiatry 1993, 56(5):481-6.

45. Bell JE: The neuropathology of adult HIV infection. Rev Neurol (Paris) 1998, 154(12):816-29.

46. Adle-Biassette $H$, Levy $Y$, Colombel M, Poron F, Natchev S, Keohane C, Gray F: Neuronal apoptosis in HIV infection in adults. Neuropathol Appl Neurobiol 1995, 21(3):218-27.

47. Galasko D: CSF tau and Abeta42: logical biomarkers for Alzheimer's disease? Neurobiol Aging 1998, 19(2):117-9.

48. Motter R, Vigo-Pelfrey C, Kholodenko D, Barbour R, Johnson-Wood K, Galasko D, Chang L, Miller B, Clark C, Green R, et al: Reduction of betaamyloid peptide42 in the cerebrospinal fluid of patients with Alzheimer's disease. Ann Neurol 1995, 38(4):643-8.

49. Brew BJ, Pemberton L, Blennow K, Wallin A, Hagberg L: CSF amyloid beta42 and tau levels correlate with AIDS dementia complex. Neurology 2005, 65(9):1490-2

50. Andreasen $N$, Minthon $L$, Vanmechelen $E$, Vanderstichele $H$, Davidsson $P$, Winblad B, Blennow K: Cerebrospinal fluid tau and Abeta42 as predictors of development of Alzheimer's disease in patients with mild cognitive impairment. Neurosci Lett 1999, 273(1):5-8.

51. Navia BA, Jordan BD, Price RW: The AIDS dementia complex: I. Clinical features. Ann Neurol 1986, 19(6):517-24.

52. Johnson RT, MCArthur JC, Narayan O: The neurobiology of human immunodeficiency virus infections. Faseb J 1988, 2(14):2970-81.

53. Guillemin GJ, Brew BJ: Implications of the kynurenine pathway and quinolinic acid in Alzheimer's disease. Redox Rep 2002, 7(4):199-206.

54. Snyder SH: Nitric oxide: first in a new class of neurotransmitters. Science 1992, 257(5069):494-6.

55. Heyes MP, Brew BJ, Martin A, Price RW, Salazar AM, Sidtis JJ, Yergey JA, Mouradian MM, Sadler AE, Keilp J, et al: Quinolinic acid in cerebrospinal fluid and serum in HIV-1 infection: relationship to clinical and neurological status. Ann Neurol 1991, 29(2):202-9.

56. Heyes MP, Mefford IN, Quearry BJ, Dedhia M, Lackner A: Increased ratio of quinolinic acid to kynurenic acid in cerebrospinal fluid of $D$ retrovirus- 
infected rhesus macaques: relationship to clinical and viral status. Ann Neurol 1990, 27(6):666-75.

57. Heyes MP, Rubinow D, Lane C, Markey SP: Cerebrospinal fluid quinolinic acid concentrations are increased in acquired immune deficiency syndrome. Ann Neurol 1989, 26(2):275-7.

58. Heyes MP, Saito K, Crowley JS, Davis LE, Demitrack MA, Der M, Dilling LA, Elia J, Kruesi MJ, Lackner A, et al: Quinolinic acid and kynurenine pathway metabolism in inflammatory and non-inflammatory neurological disease. Brain 1992, 115(Pt 5):1249-73.

59. Nath A, Geiger J: Neurobiological aspects of human immunodeficiency virus infection: neurotoxic mechanisms. Prog Neurobiol 1998, 54(1):19-33.

60. Wilt SG, Milward E, Zhou JM, Nagasato K, Patton H, Rusten R, Griffin DE, O'Connor M, Dubois-Dalcq M: In vitro evidence for a dual role of tumor necrosis factor-alpha in human immunodeficiency virus type 1 encephalopathy. Ann Neurol 1995, 37(3):381-94.

61. Wesselingh SL, Takahashi K, Glass JD, McArthur JC, Griffin JW, Griffin DE: Cellular localization of tumor necrosis factor mRNA in neurological tissue from HIV-infected patients by combined reverse transcriptase/ polymerase chain reaction in situ hybridization and immunohistochemistry. J Neuroimmunol 1997, 74(1-2):1-8.

62. Byrne Gl, Lehmann LK, Kirschbaum JG, Borden EC, Lee CM, Brown RR: Induction of tryptophan degradation in vitro and in vivo: a gammainterferon-stimulated activity. J Interferon Res 1986, 6(4):389-96.

63. Fuchs D, Shearer GM, Boswell RN, Lucey DR, Clerici M, Reibnegger G, Werner ER, Zajac RA, Wachter H: Negative correlation between blood cell counts and serum neopterin concentration in patients with HIV-1 infection. Aids 1991, 5(2):209-12.

64. Werner ER, Bitterlich G, Fuchs D, Hausen A, Reibnegger G, Szabo G, Dierich MP, Wachter H: Human macrophages degrade tryptophan upon induction by interferon-gamma. Life Sci 1987, 41(3):273-80.

65. Schmidtmayerova H, Nottet HS, Nuovo G, Raabe T, Flanagan CR, Dubrovsky L, Gendelman HE, Cerami A, Bukrinsky M, Sherry B: Human immunodeficiency virus type 1 infection alters chemokine beta peptide expression in human monocytes: implications for recruitment of leukocytes into brain and lymph nodes. Proc Natl Acad Sci USA 1996, 93(2):700-4.

66. Kure K, Weidenheim KM, Lyman WD, Dickson DW: Morphology and distribution of HIV-1 gp41-positive microglia in subacute AIDS encephalitis. Pattern of involvement resembling a multisystem degeneration. Acta Neuropathol 1990, 80(4):393-400.

67. Gullotta F, Kuchelmeister K, Masini T, Ghidoni P, Cappricci E: [The morphology of HIV encephalopathy]. Zentralbl Allg Pathol 1989, 135(1):5-13.

68. Fischer-Smith T, Bell C, Croul S, Lewis M, Rappaport J: Monocyte/ macrophage trafficking in acquired immunodeficiency syndrome encephalitis: lessons from human and nonhuman primate studies. $J$ Neurovirol 2008, 14(4):318-26.

69. Gras $\mathrm{G}$, Kaul M: Molecular mechanisms of neuroinvasion by monocytesmacrophages in HIV-1 infection. Retrovirology 7:30.

70. Edelman M, Birkenhauer MC, Steinberg JJ, Dickson DW, Casadevall A, Lee SC: Microglial nodule encephalitis: limited CNS infection despite disseminated systemic cryptococcosis. Clin Neuropathol 1996, 15(1):30-3.

71. Persidsky Y, Ghorpade A, Rasmussen J, Limoges J, Liu XJ, Stins M, Fiala M, Way D, Kim KS, Witte MH, Weinand M, Carhart L, Gendelman HE: Microglial and astrocyte chemokines regulate monocyte migration through the blood-brain barrier in human immunodeficiency virus-1 encephalitis. Am J Pathol 1999, 155(5):1599-611.

72. Nelson PT, Soma LA, Lavi E: Microglia in diseases of the central nervous system. Ann Med 2002, 34(7-8):491-500

73. Michaels J, Price RW, Rosenblum MK: Microglia in the giant cell encephalitis of acquired immune deficiency syndrome: proliferation, infection and fusion. Acta Neuropathol 1988, 76(4):373-9.

74. Liner KJ, Hall CD, Robertson KR: Effects of antiretroviral therapy on cognitive impairment. Curr HIV/AIDS Rep 2008, 5(2):64-71.

75. Ferrando SJ: Diagnosis and treatment of HIV-associated neurocognitive disorders. New Dir Ment Health Serv 2000, , 87: 25-35.

76. Boisse L, Gill MJ, Power C: HIV infection of the central nervous system: clinical features and neuropathogenesis. Neurol Clin 2008, 26(3):799-819, $x$

77. Lorenzo A, Yankner BA: Amyloid fibril toxicity in Alzheimer's disease and diabetes. Ann N Y Acad Sci 1996, 777:89-95.
78. Lorenzo A, Yankner BA: Beta-amyloid neurotoxicity requires fibril formation and is inhibited by congo red. Proc Natl Acad Sci USA 1994, 91(25):12243-7.

79. Takashima A, Noguchi K, Michel G, Mercken M, Hoshi M, Ishiguro K, Imahori K: Exposure of rat hippocampal neurons to amyloid beta peptide (25-35) induces the inactivation of phosphatidyl inositol-3 kinase and the activation of tau protein kinase $1 /$ glycogen synthase kinase-3 beta. Neurosci Lett 1996, 203(1):33-6.

80. Giunta B, Obregon D, Hou H, Zeng J, Sun N, Nikolic V, Ehrhart J, Shytle D, Fernandez $F$, Tan J: EGCG mitigates neurotoxicity mediated by HIV-1 proteins gp120 and Tat in the presence of IFN-gamma: role of JAK/ STAT1 signaling and implications for HIV-associated dementia. Brain Res 2006, 1123(1):216-25.

81. Giulian D, Haverkamp LJ, Li J, Karshin WL, Yu J, Tom D, Li X, Kirkpatrick JB: Senile plaques stimulate microglia to release a neurotoxin found in Alzheimer brain. Neurochem Int 1995, 27(1):119-37.

82. Tan J, Town T, Mullan M: CD45 inhibits CD40L-induced microglial activation via negative regulation of the Src/p44/42 MAPK pathway. J Biol Chem 2000, 275(47):37224-31.

83. McGeer PL, Itagaki S, Boyes BE, McGeer EG: Reactive microglia are positive for HLA-DR in the substantia nigra of Parkinson's and Alzheimer's disease brains. Neurology 1988, 38(8):1285-91.

84. McGeer EG, McGeer PL: The role of the immune system in neurodegenerative disorders. Mov Disord 1997, 12(6):855-8.

85. McGeer PL, McGeer EG, Kawamata T, Yamada T, Akiyama H: Reactions of the immune system in chronic degenerative neurological diseases. Can $J$ Neurol Sci 1991, 18(3 Suppl):376-9.

86. Rozemuller JM, Eikelenboom P, Stam FC: Role of microglia in plaque formation in senile dementia of the Alzheimer type. An immunohistochemical study. Virchows Arch B Cell Pathol Ind Mol Pathol 1986, 51(3):247-54.

87. Rozemuller JM, Eikelenboom P, Pals ST, Stam FC: Microglial cells around amyloid plaques in Alzheimer's disease express leucocyte adhesion molecules of the LFA-1 family. Neurosci Lett 1989, 101(3):288-92.

88. Kiebala M, Polesskaya O, Yao Z, Perry SW, Maggirwar SB: Nuclear factorkappa B family member RelB inhibits human immunodeficiency virus-1 Tat-induced tumor necrosis factor-alpha production. PLoS One 5(7): e11875.

89. Rappaport J, Joseph J, Croul S, Alexander G, Del Valle L, Amini S, Khalili K: Molecular pathway involved in HIV-1-induced CNS pathology: role of viral regulatory protein, Tat. J Leukoc Biol 1999, 65(4):458-65.

90. Wisniewski HM, Wegiel J, Wang KC, Kujawa M, Lach B: Ultrastructural studies of the cells forming amyloid fibers in classical plaques. Can J Neurol Sci 1989, 16(4 Suppl):535-42.

91. Klegeris A, Walker DG, McGeer PL: Interaction of Alzheimer beta-amyloid peptide with the human monocytic cell line THP-1 results in a protein kinase C-dependent secretion of tumor necrosis factor-alpha. Brain Res 1997, 747(1):114-21.

92. Klegeris A, McGeer PL: beta-amyloid protein enhances macrophage production of oxygen free radicals and glutamate. J Neurosci Res 1997, 49(2):229-35.

93. Klegeris A, Walker DG, McGeer PL: Activation of macrophages by Alzheimer beta amyloid peptide. Biochem Biophys Res Commun 1994, 199(2):984-91.

94. McDonald DR, Brunden KR, Landreth GE: Amyloid fibrils activate tyrosine kinase-dependent signaling and superoxide production in microglia. J Neurosci 1997, 17(7):2284-94.

95. McDonald DR, Bamberger ME, Combs CK, Landreth GE: beta-Amyloid fibrils activate parallel mitogen-activated protein kinase pathways in microglia and THP1 monocytes. J Neurosci 1998, 18(12):4451-60.

96. Combs CK, Johnson DE, Cannady SB, Lehman TM, Landreth GE: Identification of microglial signal transduction pathways mediating a neurotoxic response to amyloidogenic fragments of beta-amyloid and prion proteins. J Neurosci 1999, 19(3):928-39.

97. Townsend KP, Town T, Mori T, Lue LF, Shytle D, Sanberg PR, Morgan D, Fernandez F, Flavell RA, Tan J: CD40 signaling regulates innate and adaptive activation of microglia in response to amyloid beta-peptide. Eur J Immunol 2005, 35(3):901-10.

98. Lorton D, Kocsis JM, King L, Madden K, Brunden KR: beta-Amyloid induces increased release of interleukin-1 beta from lipopolysaccharide-activated human monocytes. J Neuroimmunol 1996, 67(1):21-9. 
99. Yankner BA, Duffy LK, Kirschner DA: Neurotrophic and neurotoxic effects of amyloid beta protein: reversal by tachykinin neuropeptides. Science 1990, 250(4978):279-82.

100. Turchan-Cholewo J, Dimayuga VM, Gupta S, Gorospe RM, Keller JN, BruceKeller AJ: NADPH oxidase drives cytokine and neurotoxin release from microglia and macrophages in response to HIV-Tat. Antioxid Redox Signal 2009, 11(2):193-204

101. Shatrov VA, Ratter F, Gruber A, Droge W, Lehmann V: HIV type 1 glycoprotein 120 amplifies tumor necrosis factor-induced NF-kappa B activation in Jurkat cells. AIDS Res Hum Retroviruses 1996, 12(13):1209-16.

102. Turchan-Cholewo J, Dimayuga FO, Gupta S, Keller JN, Knapp PE, Hauser KF, Bruce-Keller AJ: Morphine and HIV-Tat increase microglial-free radical production and oxidative stress: possible role in cytokine regulation. J Neurochem 2009, 108(1):202-15.

103. Aksenov MY, Hasselrot U, Wu G, Nath A, Anderson C, Mactutus CF, Booze RM: Temporal relationships between HIV-1 Tat-induced neuronal degeneration, OX-42 immunoreactivity, reactive astrocytosis, and protein oxidation in the rat striatum. Brain Res 2003, 987(1):1-9.

104. Kornbluth RS: The emerging role of CD40 ligand in HIV infection. J Leukoc Biol 2000, 68(3):373-82

105. Giunta B, Rezai-Zadeh K, Tan J: Impact of the CD40-CD40L dyad in Alzheimer's disease. CNS Neurol Disord Drug Targets 9(2):149-55.

106. Giunta B, Figueroa KP, Town T, Tan J: Soluble Cd40 Ligand in Dementia. Drugs Future 2009, 34(4):333-340.

107. Heeschen C, Dimmeler S, Hamm CW, van den Brand MJ, Boersma E, Zeiher AM, Simoons ML, CAPTURE Study Investigators: Soluble CD40 ligand in acute coronary syndromes. N Engl J Med 2003, 348(12):1104-11.

108. Tsakiris DA, Tschöpl M, Wolf F, Labs KH, Jäger KA, Marbet GA: Platelets and cytokines in concert with endothelial activation in patients with peripheral arterial occlusive disease. Blood Coagul Fibrinolysis 2000, 11(2):165-73.

109. Devaraj S, Glaser N, Griffen S, Wang-Polagruto J, Miguelino E, Jialal I: Increased monocytic activity and biomarkers of inflammation in patients with type 1 diabetes. Diabetes 2006, 55(3):774-9.

110. Chai $H$, Yan S, Wang H, Zhang R, Lin PH, Yao Q, Chen C: CD40 ligand increases expression of its receptor CD40 in human coronary artery endothelial cells. Surgery 2006, 140(2):236-42.

111. Gerritse K, Laman JD, Noelle RJ, Aruffo A, Ledbetter JA, Boersma WJ, Claassen E: CD40-CD40 ligand interactions in experimental allergic encephalomyelitis and multiple sclerosis. Proc Natl Acad Sci USA 1996, 93(6):2499-504.

112. Shapshak P, Duncan R, Minagar A, Rodriguez de la Vega P, Stewart RV, Goodkin K: Elevated expression of IFN-gamma in the HIV-1 infected brain. Front Biosci 2004, 9:1073-81.

113. Aloisi F, Penna G, Polazzi E, Minghetti L, Adorini L: CD40-CD154 interaction and IFN-gamma are required for IL-12 but not prostaglandin E2 secretion by microglia during antigen presentation to Th1 cells. J Immunol 1999, 162(3):1384-91.

114. Nguyen VT, Walker WS, Benveniste EN: Post-transcriptional inhibition of CD40 gene expression in microglia by transforming growth factor-beta. Eur J Immunol 1998, 28(8):2537-48.

115. Togo T, Akiyama H, Kondo H, Ikeda K, Kato M, Iseki E, Kosaka K: Expression of CD40 in the brain of Alzheimer's disease and other neurological diseases. Brain Res 2000, 885(1):117-21.

116. Suo Z, Tan J, Placzek A, Crawford F, Fang C, Mullan M: Alzheimer's betaamyloid peptides induce inflammatory cascade in human vascular cells: the roles of cytokines and CD40. Brain Res 1998, 807(1-2):110-7.

117. Tan J, Town T, Paris D, Mori T, Suo Z, Crawford F, Mattson MP, Flavell RA, Mullan M: Microglial activation resulting from CD40-CD40L interaction after beta-amyloid stimulation. Science 1999, 286(5448):2352-5.

118. Tan J, Placzek A, Crawford F, Fang C, Mullan M: Induction of CD40 on human endothelial cells by Alzheimer's beta-amyloid peptides. Brain Res Bull 1999, 50(2):143-8.

119. Hollenbaugh D, Mischel-Petty N, Edwards CP, Simon JC, Denfeld RW, Kiener PA, Aruffo A: Expression of functional CD40 by vascular endothelial cells. J Exp Med 1995, 182(1):33-40.

120. Karmann K, Hughes CC, Schechner J, Fanslow WC, Pober JS: CD40 on human endothelial cells: inducibility by cytokines and functional regulation of adhesion molecule expression. Proc Natl Acad Sci USA 1995, 92(10):4342-6.

121. Moses AV, Williams SE, Strussenberg JG, Heneveld ML, Ruhl RA, Bakke AC, Bagby GC, Nelson JA: HIV-1 induction of CD40 on endothelial cells promotes the outgrowth of AIDS-associated B-cell lymphomas. Nat Med 1997, 3(11):1242-9.

122. Sui Z, Sniderhan LF, Schifitto G, Phipps RP, Gelbard HA, Dewhurst S, Maggirwar SB: Functional synergy between CD40 ligand and HIV-1 Tat contributes to inflammation: implications in HIV type 1 dementia. J Immunol 2007, 178(5):3226-36.

123. Eilers $M$, Roy $U$, Mondal D: MRP (ABCC) transporters-mediated efflux of anti-HIV drugs, saquinavir and zidovudine, from human endothelial cells. Exp Biol Med (Maywood) 2008, 233(9):1149-60.

124. Sipsas NV, Sfikakis pp, Kontos A, Kordossis T: Levels of soluble CD40 ligand (CD154) in serum are increased in human immunodeficiency virus type 1-infected patients and correlate with CD4(+) T-cell counts. Clin Diagn Lab Immunol 2002, 9(3):558-61.

125. Piguet PF, Kan CD, Vesin C, Rochat A, Donati Y, Barazzone C: Role of CD40CVD40L in mouse severe malaria. Am J Pathol 2001, 159(2):733-42.

126. Ishikawa M, Vowinkel T, Stokes KY, Arumugam TV, Yilmaz G, Nanda A, Granger DN: CD40/CD40 ligand signaling in mouse cerebral microvasculature after focal ischemia/reperfusion. Circulation 2005, 111(13):1690-6.

127. Sitati E, McCandless EE, Klein RS, Diamond MS: CD40-CD40 ligand interactions promote trafficking of CD8+ T cells into the brain and protection against West Nile virus encephalitis. J Virol 2007, 81(18):9801-11.

128. Ramirez SH, Fan S, Dykstra H, Reichenbach N, Del Valle L, Potula R, Phipps RP, Maggirwar SB, Persidsky Y: Dyad of CD40/CD40 ligand fosters neuroinflammation at the blood-brain barrier and is regulated via JNK signaling: implications for HIV-1 encephalitis. J Neurosci 30(28):9454-64.

129. Tan J, Town T, Saxe M, Paris D, Wu Y, Mullan M: Ligation of microglial CD40 results in p44/42 mitogen-activated protein kinase-dependent TNF-alpha production that is opposed by TGF-beta 1 and IL-10. J Immunol 1999, 163(12):6614-21.

130. Todd Roach J, Volmar CH, Dwivedi S, Town T, Crescentini R, Crawford F, Tan J, Mullan M: Behavioral effects of CD40-CD40L pathway disruption in aged PSAPP mice. Brain Res 2004, 1015(1-2):161-8.

131. Tan J, Town T, Mori T, Wu Y, Saxe M, Crawford F, Mullan M: CD45 opposes beta-amyloid peptide-induced microglial activation via inhibition of $\mathrm{p} 44 /$ 42 mitogen-activated protein kinase. J Neurosci 2000, 20(20):7587-94.

132. Irie-Sasaki J, Sasaki T, Penninger JM: CD45 regulated signaling pathways. Curr Top Med Chem 2003, 3(7):783-96.

133. Irie-Sasaki J, Sasaki T, Matsumoto W, Opavsky A, Cheng M, Welstead G, Griffiths E, Krawczyk C, Richardson CD, Aitken K, Iscove N, Koretzky G, Johnson P, Liu P, Rothstein DM, Penninger JM: CD45 is a JAK phosphatase and negatively regulates cytokine receptor signalling. Nature 2001, 409(6818):349-54.

134. Baur A, Garber S, Peterlin BM: Effects of CD45 on NF-kappa B. Implications for replication of HIV-1. J Immunol 1994, 152(3):976-83.

135. Koronyo-Hamaoui M, Ko MK, Koronyo Y, Azoulay D, Seksenyan A, Kunis G, Pham M, Bakhsheshian J, Rogeri P, Black KL, Farkas DL, Schwartz M: Attenuation of AD-like neuropathology by harnessing peripheral immune cells: local elevation of IL-10 and MMP-9. J Neurochem 2009, 111(6):1409-24.

136. Townsend KP, Vendrame M, Ehrhart J, Faza B, Zeng J, Town T, Tan J: CD45 isoform RB as a molecular target to oppose lipopolysaccharide-induced microglial activation in mice. Neurosci Lett 2004, 362(1):26-30.

137. Mahalingam M, Pozniak A, McManus TJ, Senaldi G, Vergani D, Peakman M: Abnormalities of CD45 isoform expression in HIV infection. Clin Immunol Immunopathol 1996, 81(2):210-4.

138. Guntermann C, Amft N, Murphy BJ, Nye KE: Impaired CD45-associated tyrosine phosphatase activity during HIV-1 infection: implications for CD3 and CD4 receptor signalling. Biochem Biophys Res Commun 1998, 252(1):69-77.

139. Kim MO, Suh HS, Si Q, Terman Bl, Lee SC: Anti-CD45RO suppresses human immunodeficiency virus type 1 replication in microglia: role of Hck tyrosine kinase and implications for AIDS dementia. J Virol 2006, 80(1):62-72.

doi:10.1186/1750-1326-6-3

Cite this article as: Salemi et al:: Flipping the switches: CD40 and CD45 modulation of microglial activation states in HIV associated dementia (HAD). Molecular Neurodegeneration 2011 6:3. 